\title{
Challenges and alternatives for the adequacy of hydrothermal carbonization of lignocellulosic biomass in cleaner production systems: A review.
}

Romario Victor Pacheco Antero*a; Andreia Cristina Fonseca Alves ${ }^{\mathrm{b}}$; Sergio Botelho de Oliveira ${ }^{\mathrm{c}}$; Satu Anneli Ojala ${ }^{\text {; }}$ Sarah Silva Brum ${ }^{\mathrm{a}}$

anstituto de Química, Universidade de Brasília. Campus Universitário Darcy Ribeiro, 70910-900, BrasíliaDF, Brasil.

bUniversidade Federal de Goiás, Rua 240, Esquina com $5^{\mathrm{a}}$ Avenida, s/n, Setor Leste Universitário, CEP: 74605-170, Goiânia/GO - Brasil.

'Instituto Federal de Goiás, Rua 75, nº46. Centro. CEP: 74055-110. Goiânia/GO - Brasil.

${ }^{\mathrm{d} U n i v e r s i t y ~ o f ~ O u l u, ~ F a c u l t y ~ o f ~ T e c h n o l o g y, ~ E n v i r o n m e n t a l ~ a n d ~ C h e m i c a l ~ E n g i n e e r i n g, ~ F I-90014 . ~ P . O . ~}$ Box 4300, Finland.

*drvictor.pacheco@outlook.com. orcid.org/0000-0002-3680-345X

\section{Introduction}

Lignocellulosic biomass (composed mainly of lignin, cellulose, and hemicellulose) is one of the most abundant resources on the planet and usable for obtaining various products. For a long time, this type of biomass was underutilized, being limited to the burning, cooking, and heating. However, it can be converted into various useful forms of energy and products of interest using thermochemical and biochemical or biological conversion processes. The conversion by biochemical or biological processes occurs naturally and includes anaerobic degradations, fermentation, and enzymatic hydrolysis, carried out by bacteria, microorganisms, and enzymes (Goyal et al., 2008), which convert biomass into various products and by-products (Cai et al., 2017). The thermochemical conversion uses heat and catalysts to transform biomass into biofuels and other value-added chemicals, occurring mainly through pyrolysis, gasification, combustion, liquefaction and hydrothermal carbonization (Adams et al., 2018; Wang et al., 2017).

The hydrothermal carbonization (HTC) is a thermochemical conversion process that occurs in hot water (subcritical) and produces gases, liquids, and solids fractions. Among the many biomass conversion technologies, the advantage of hydrothermal carbonization is that wet biomass with a water content of 70-90\% by weight can be converted without prior drying (Kruse e Dahmen, 2018). Among the main product of the technique is hydrochar (solid fraction) with great applications in the agricultural, medicinal, environmental, energy, etc. (Fang et al., 2018; Heidari et al., 2018; Kambo e Dutta, 2015). However, liquid (water soluble) and gaseous (mainly $\mathrm{CO}_{2}$ ) by-products are also produced (Heidari et al., 2018). The method has been proving versatile to obtain various products from different types of biomass, using lower temperatures and reactional conditions lighter compared to other thermal conversion processes (Gallifuoco et al., 2017), thus being considered an eco-friendly methodology. 
Although described with a sustainable methodology, hydrothermal carbonization needs to overcome some challenges to fit clean production processes. In this context, one of the main bottlenecks associated with hydrothermal carbonization concerns the excessive use of water during the process. Considering that one of the greatest challenges facing humanity today is the scarcity of drinking water, due to the degradation of aquatic environments and the constant irregular discharges of contaminants from various sources (Anumol et al., 2016; Sophia e Lima, 2018), hydrothermal carbonization faces a double challenge to adapt to the processes. of clean production. Initially, it is necessary to create alternatives for reducing excessive water expenditure. Next, it is important to give an appropriate destination to the aqueous fraction originated after hydrothermal treatment. An alternative that has been presented in the literature to reduce the mentioned problems concerns the recirculation of process water (Chen et al., 2018; Kambo et al., 2018).

In addition to recirculating processes, strategies for reuse and degradation of the residual fractions obtained during the process, reuse of hydrochar in adsorption processes, obtaining activated carbons at lower temperatures and without chemical reagents, use of the technique in a biorefinery system for the simultaneous production of various materials, etc., are some of the gaps still present to consolidate the technique as a clean, environmental and sustainable production. Thus, considering the lack in the current literature regarding these discussions, this paper stands out from those available in the literature because it focuses on lignocellulosic biomass and presents not only the fundamentals and applications of the technique but also the challenges to be overcome in a clean production system. The development of the methodology, as well as the application of the obtained products, was discussed focusing on the awareness of the need to value the ecological systems and the natural capital necessary for human well-being. In this context, we present the challenges associated with the use of hydrothermal carbonization products, along with the social and environmental benefits, rather than just prioritizing economic growth. To the authors' knowledge, there are no review articles in which the discussions mentioned here were presented together, considering the sustainability of the process. In this aspect, we discuss the possibility of changes in current standards and the importance of applying the technique in models that aim for greater social and environmental sustainability in the industrial system.

\section{Methodological approach}

This paper presents a critical review on the topic "hydrothermal carbonization of lignocellulosic biomass and the challenges for cleaner production.". The method used in the elaboration of the manuscript consisted of two steps: (i) identify the central theme of the research, through a general literature search using the terms "hydrothermal carbonization and lignocellulosic biomass" and (ii) map the publications about the applications. of hydrochars 
derived from hydrothermal carbonization of lignocellulosic biomass, as well as studies related to water recirculation of the process. At this stage we considered the articles addressing the applications of hydrochar in agricultural, energy, environmental, medical, adsorbent and as precursors for obtaining activated carbons. From the information collected at this stage, for each potential application of hydrochar presented the challenges for greater social and environmental sustainability of hydrothermal carbonization. The literature gathered for the writing included mainly recent articles, especially between 2014 and 2019. The most accessed articles in the period were also reviewed to verify and categorize the themes. To ensure the identification of all relevant literature, review articles were also analyzed. However, the focus was on research articles, analyzing abstracts and the authors' main conclusions. The information contained in the manuscript was collected using the keywords "hydrothermal carbonization, hydrochar, lignocellulosic biomass, soil amendment, solid fuel, alternative adsorbents, water recirculation's etc". The data available was obtained using the keywords mentioned in several research platforms, such as Science Direct, NCBI, Springer, Taylor \& Francis, and ACS.

\section{General concepts of hydrothermal carbonization}

Initial works related to hydrothermal carbonization yielded the Nobel Prize to Friedrich Bergius in 1913, describing the process of obtaining coal in his "theory of coal formation." Bergius heated different types of biomass in a tray with water varying the scale of time (10 to $30 \mathrm{~h}$ ) and temperature (170 to $\left.340{ }^{\circ} \mathrm{C}\right)$, being able to artificially examine and produce several stages of carbonization (Tekin et al., 2014). The technique simulates the natural coalification processes, responsible for the formation of fossil materials with high carbonaceous content (Titirici and Antonietti, 2010; Wohlgemuth, 2012). Currently, the process has become known, and the growing number of publications in recent years shows the worldwide interest in research in this area, as shown in Fig. 1. Considering the huge volume of research related to the subject, the improvement of productivity, better use of resources, restructuring of production profiles, consumption and transformation should be considered. These issues are of great importance to broaden the current discussions and allow advances in research and practices of cleaner production, environmental and sustainability of hydrothermal carbonization methodology. 


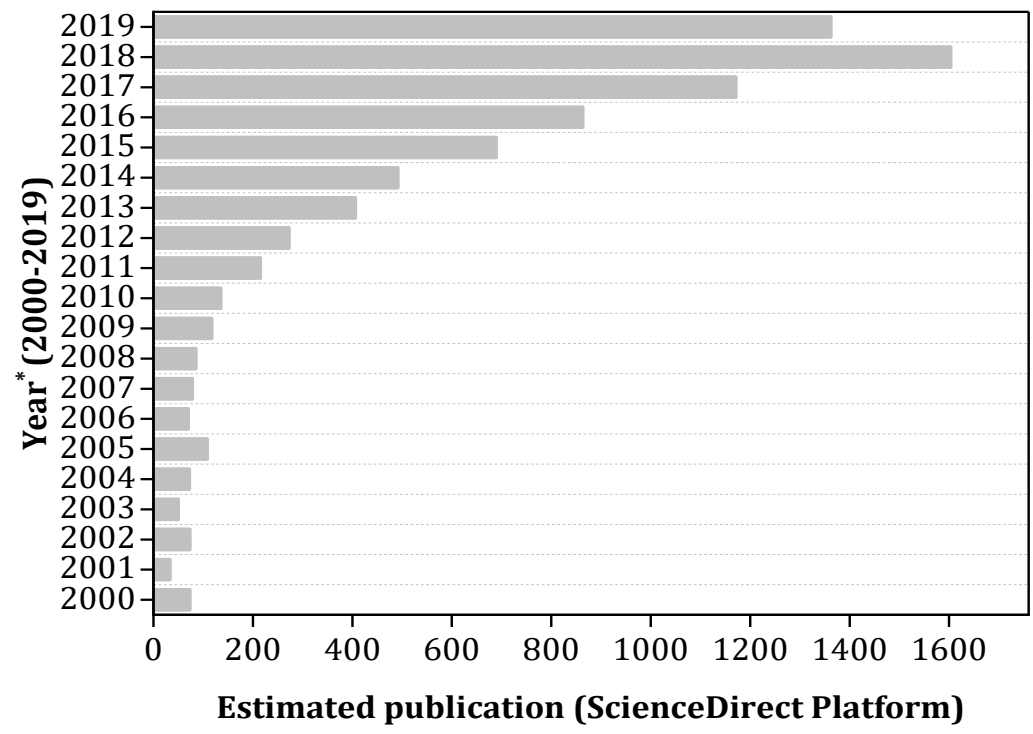

Fig. 1. Articles published in the last 20 years on the ScienceDirect platform maintained by Elsevier with the keyword "hydrothermal carbonization". * Data for 2019 only refer to the first semester.

Hydrothermal carbonization is mentioned as an eco-friendly method for converting lignocellulosic biomass into different value-added products (Fang et al., 2018; Kumar et al., 2018). From the methodology, a solid material (hydrochar), a liquid phase (dissolved organic matter or residual water) and gases are obtained (Kambo and Dutta, 2015; Liu et al., 2018), as shown in Fig. 2. During the process, the precursor is placed in an autoclave, preferably using water as a solvent. This condition eliminates the need for prior drying as occurs in pyrolysis, allowing wet biomass with a 70-90\% natural water content to be used (Kruse e Dahmen, 2018). The autoclave is then heated to the desired temperature (170-250 ${ }^{\circ} \mathrm{C}$ ) (Fang et al., 2018), where the pressure is self-generated due to the presence of water in the subcritical. These factors will be responsible for the simultaneous reactions that will occur inside the autoclave and will lead to the final composition of the products obtained.

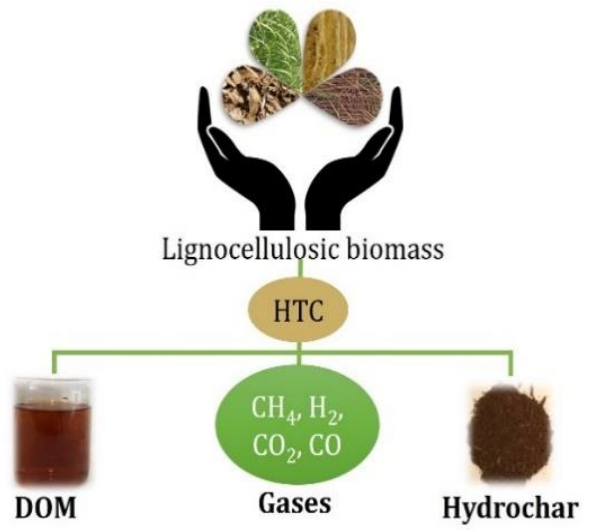

Fig. 2. Products obtained from hydrothermal carbonization of lignocellulosic biomass. HTC: Hydrothermal carbonization. DOM: Dissolved organic matter.

Several advantages are presented in the literature for hydrothermal carbonization, such as lower emission of by-products than pyrolysis (Fang et al., 2018; Kambo and Dutta, 2015). In 
addition, precursor materials with high moisture content produce low amounts of solid after drying process, which makes them inefficient for pyrolysis. Therefore, a greater variety of biomass can be considered for hydrothermal carbonization. Hydrothermal carbonization also produces a more solid material and uses smaller amounts of energy than pyrolysis (Fang et al., 2018). This characteristic is due to the fact that drying of the precursor is not necessary, as well as the use of temperatures lower than pyrolysis (300-600 ${ }^{\circ} \mathrm{C}$ ) (Fang et al., 2018; Kumar et al., 2018).

\section{Variables involved in hydrothermal carbonization}

The temperature is one of the main variables in hydrothermal carbonization, and which significantly influences the biomass conversion process from the degradation of the structural components. This process occurs due to the breaking of the chemical bonds of the biomass structural components, which occurs by the joint action of hydrothermal reactions as a consequence of the temperature (Zhang et al., 2019). As discussed previously, each component is individually affected because they suffer degradation at different temperature ranges. The literature reports temperature values between $175^{\circ} \mathrm{C}$ and $300{ }^{\circ} \mathrm{C}$ for different types of biomass, as shown in Table 1 . Generally, temperatures between 150 and $200{ }^{\circ} \mathrm{C}$ favor the formation of solid products (Nizamuddin et al., 2017). According to the authors, the higher the temperature, the higher the carbonization and the more intense will be the dehydration and decarboxylation reactions. These conditions will also affect the yield of liquid and gaseous products. This fact was observed by Nakason et al. (2018b), who worked with the production of hydrochar from coconut husk and rice husk. Erdogan et al. (2015) also discuss the reduction of yield with the increase in temperature is also related to dehydration reactions of decarboxylation. In addition to the reactions, the authors punctuate the joint action of the extractable compounds, which are simultaneously dissolved under subcritical conditions of the water, thus causing a lower yield in hydrochar production.

The hydrothermal carbonization occurs in a relatively slow reaction process. Current publications report responses in processes occurring in a time interval between 30 minutes to 12 $\mathrm{h}$ (Chen et al., 2017), and residence times of 1 and $2 \mathrm{~h}$ are the most used (Missaoui et al., 2017). Missaoui et al. (2017) worked with reaction times between 5 to 120 minutes and temperature of $215{ }^{\circ} \mathrm{C}$ for hydrochar production from the olive pomace. The results showed little variation in yield, with a difference of only $9 \%$ between the lowest and highest time. Chen et al. (2017) used in their study reaction times of 1,6 and $12 \mathrm{~h}$ and temperature $190^{\circ} \mathrm{C}$. Comparing with the reaction time of $1 \mathrm{~h}$, the time of $6 \mathrm{~h}$ showed a yield of about $25 \%$ greater and the time of $12 \mathrm{~h}$ about $29 \%$ greater than the yield of $1 \mathrm{~h}$. This increase in yield of hydrochar occurs due to polymerization of compounds dissolved in the liquid phase, which leads to precipitation of insoluble solids, thus increasing the final yield of solid in the process (Funke and Ziegler, 2010b). In addition, to yield, 
the textural features such as surface area and porous structure of the produced hydrochars are also exposed to the significant effects of residence time. However, it was observed that the literature presents no studies and discussions analyzing this relationship. This deficiency is due in large part to the low specific surface areas observed in the hydrochar as a consequence of the weak porous structure developed. In this respect, the specific surface areas observed are generally attributed to the external surface area.

Another parameter still little discussed in the HTC literature are the catalysts. The use of catalysts has the purpose of accelerating reaction rates, modifying or adapting the reaction path and acting on the biomass decomposition. Studies indicate that the use of catalysts reduces the activation energy in the hydrolysis of biomass, and at the same time, favors the production of high oxygenated functional groups, even in biomass with high lignin content, low temperatures and lower reaction periods. These oxygenated functional groups formed on the surface of the hydrochar act positively favoring processes of chemical activation (Jain et al., 2016). Homogeneous catalysts are the most common due to their higher activity when compared to heterogeneous catalysts. Heterogeneous catalysts suffer loss of function throughout the process due to conditions of high pressure, temperature and subcritical water stage. However, unlike homogeneous catalysts, heterogeneous catalysts are easy to separate and reuse, which is an advantage in industrial processes as it provides cost savings. There is a lack of studies in the literature that focus on the stability of heterogeneous catalysts during hydrothermal carbonization processes. Ensuring the activity of these catalysts is still a challenge that needs to be explored.

\section{Lignocellulosic biomass: general definitions and structure}

Biomass is defined as an organic material of vegetable or animal origin that has sunlight stored in the form of chemical energy and characterized as lignocellulosic and non-cellulosic (Heidari et al., 2018). The non-lignocellulosic biomass generally comprises sewage sludge, animal wastes, etc., formed mainly by fatty acids, proteins and small amounts of hemicellulose, cellulose, and lignin (Achinas et al., 2017; Heidari et al., 2018). Lignocellulosic biomass refers to the type of biomass formed mainly by cellulose, hemicellulose, and lignin, as well as a small fraction of extractives and ashes. In this type of biomass are included forest and agricultural residues, wood chips, straws, bark, etc., (Wang et al., 2017).

As shown in Fig. 6, the major components of the lignocellulosic biomass are unevenly distributed in the cell wall, functioning as a connection skeleton between them and the other constituents. Cellulose macromolecules meet regularly to form resistant microfibrils, which function as skeletal material of the cell wall, while the inner space is coated with amorphous hemicellulose and lignin (Wang et al., 2017). Cellulose binds to hemicellulose or lignin molecules mainly through hydrogen bonds, whereas the connections between hemicellulose and 
lignin include hydrogen bonds and covalent bonds (Vorwerk et al., 2004). The contents of cellulose, hemicellulose, and lignin in the biomass vary according to the type of biomass. The cellulose content may reach $40-60 \%$, the hemicellulose content between $15-30 \%$ and the lignin content of approximately 10-25\% (Wang et al., 2017).

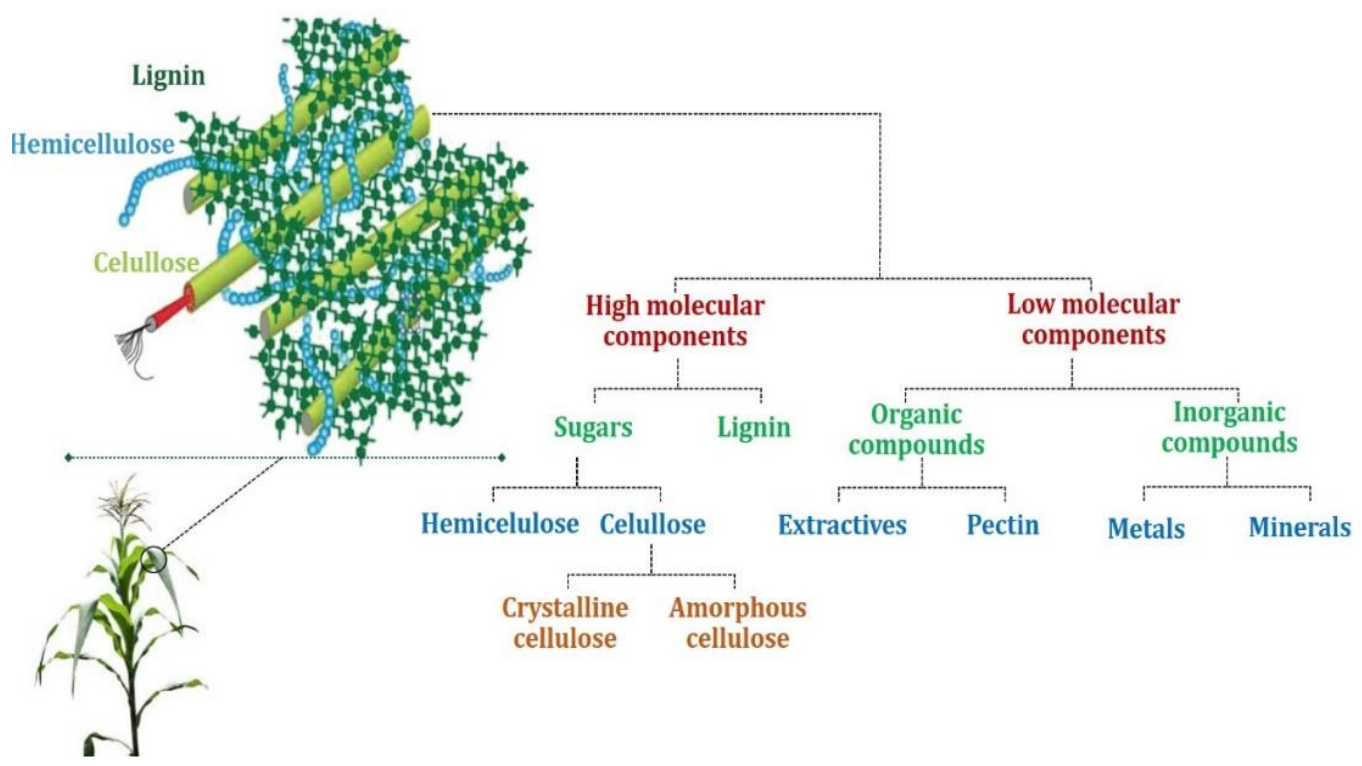

Fig. 3. Components present in the lignocellulosic biomass structure. Adapted from Nanda et al. 2016; Wang et al. 2017.

For several years most of the literature published in the journals on hydrothermal carbonization of biomass has focused mainly on the carbonization of model compounds, as pure cellulose. However, in recent years, HTC's efficiency as a cost-effective approach to transforming lignocellulosic biomass into value-added products has led to the processing of different types of biomass under different reaction conditions, as concisely noted in Tab. 1 . The use of milder temperatures $\left(140{ }^{\circ} \mathrm{C}\right.$ and $\left.160^{\circ} \mathrm{C}\right)$ is observed in a particular case. For this interval, only part of the biomass components is degraded and the HTC is used only as a pretreatment of the lignocellulosic biomass for a partial deconstruction of the lignocellulosic matrix.

\section{Table 1}

Reaction temperature ranges used in the hydrothermal carbonization process of different biomasses.

\begin{tabular}{lll}
\hline Biomass used & Temperature $\left({ }^{\circ} \mathbf{C}\right)$ & Reference \\
\hline Tobacco stalk & $180,200,220,240,260$ & (Cai et al., 2016) \\
Eucalyptus bark & $220,240,275,300$ & (Gao et al., 2016) \\
Watermelon pell & 190,260 & (Chen et al., 2017) \\
Olive pomace & $180,200,215,230,250$ & (Missaoui et al., 2017) \\
Pine & $180,220,240$ & (Wu et al., 2017) \\
Coconut husk and rice husk & $140,160,180,200$ & (Nakason et al., 2018a) \\
Coconut shell & 210 & (Tu et al., 2019) \\
\hline
\end{tabular}




\section{Effects of hydrothermal carbonization on lignocellulosic biomass}

During the hydrothermal carbonization, the degradation/depolymerization of these components occurs at lower temperatures (Yan et al., 2009). In hydrothermal conditions, the degradation of hemicellulose and cellulose starts at about $160-180^{\circ} \mathrm{C}$, where most of the lignin remains stable to near or above the critical point of the water. During treatment, cellulose and hemicellulose are partially or totally degraded, forming hydrochar with high lignin content (Kambo and Dutta, 2015). Especially on hemicellulose, the degradation will result in the formation of 2,5-HMF (hydroxymethylfurfural) (Funke and Ziegler, 2010a). Studies indicate that the concentration of this compound in the aqueous phase of the hydrothermal carbonization is linear to the increase of the reaction temperature (Yan et al., 2010). Thus, deposition of 2,5HMF in the porous structure of the hydrochar can occur and increase the energy density of these materials. This effect is used to explain the differences in the high energy density of the hydrochar compared to the biochar (Kambo and Dutta, 2015).

Similar to hemicellulose, lignin begins to degrade at temperatures above $200{ }^{\circ} \mathrm{C}$, however, only minimal amounts are dissolved during hydrothermal treatment due to the aromatic and polymeric structure of high molecular weight (Wang et al., 2018). The reactive mechanisms of lignin during hydrothermal carbonization are complex, and only a few monomers, such as guaiacol, eugenol (Besse et al., 2015) etc., have been used so far to explore the reaction pathways. Zhang et al. (2008) argue that as the temperatures of the hydrothermal reactions increase, the Kraft lignin becomes more soluble in water, causing the solubilized fragments to interact and condense to a solid residue (hydrochar). Fang et al. (2008) in another study, discuss that the lignin decomposes by hydrolysis and dealkylation in a homogeneous reaction, giving rise to phenolic products (syringes, guaiacols, catechols, and phenols).

Although several reaction mechanisms are explored to explain the hydrothermal carbonization effects on the individual lignocellulosic components, the degradation of the crude biomass is different due to the strong connections between the components. Due to the complex structure, the crude lignocellulosic biomass requires greater activation energy to break the structure of the individual components (Wang et al., 2018). Generally, the level of degradation of the lignocellulosic components follows the order hemicellulose> cellulose> lignin, considering the same reaction condition. In this order, lignin presents greater stability due to the phenolic structure, which also affects the condensation reactions (Kang et al., 2012; Wang et al., 2018). Compared with cellulose that has a partially crystalline structure, the hemicellulose has an amorphous structure, lower molar mass and less degree of polymerization (approximately 50-200 units), which explains its lower hydrothermal carbonization stability (Wang et al., 2018) 


\section{Potential applications of hydrochar and challenges for a greater social and environmental sustainability.}

Awareness of the need to value environmental resources and the natural capital needed for human well-being is not new (Bocken et al., 2014). Thus, the development and use of new products must fit into a sustainable context in which responses to environmental change must necessarily be parallel to economic and social change. There is a diversity of work in the literature emphasizing the benefits, potentialities and multi functionalities of hydrochar (Heidari et al., 2018; Kambo e Dutta, 2015; S. Zhang et al., 2019b). However, hydrothermal carbonization needs to be thought of as a system designed to maximize social and environmental benefits rather than prioritizing economic growth alone. A closed system in which nothing can be wasted or disposed of in the untreated environment, which reuses, repairs, and repairs rather than recycles (Bocken et al., 2014) In this context, in order to meet the pressing challenges of a sustainable future, hydrochar development and applications need to stick to some strategies

7.1. Soil amendment: sequestration for reducing greenhouse gas (GHG) emission, fertility and water retention

In the agricultural area, the use of hydrochar is related to soil alteration, nutrient release, mineralization, germination, growth of different crops, water retention, mitigation of climate change, etc., (Fang et al., 2018; Heidari et al., 2018; Zhang et al., 2019). These features can be summarized into three main groups: reducing greenhouse gas emission, soil fertility and soil water retention, as shown in Fig.5.

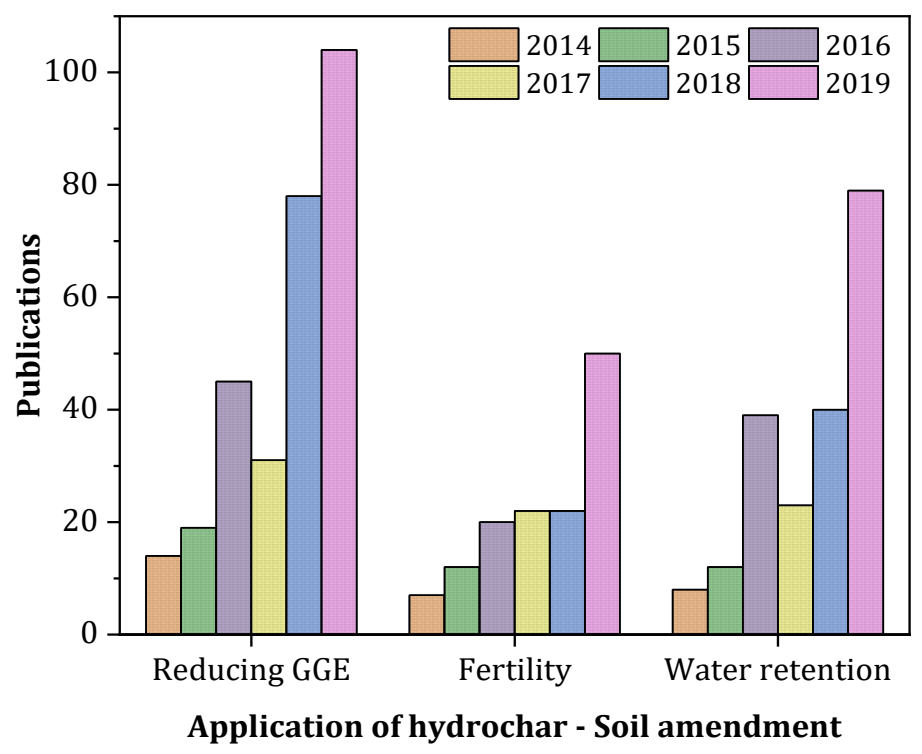

Fig. 4. Number of publications in the last 6 years related to potential applications of hydrochar in the agricultural area.

The use of hydrochar as fertilizer is the smallest number of publications. This factor can be explained by the low nutrient content present in hydrochar, which makes them insufficient as fertilizers alone. An alternative in this regard is adding them to the soil to improve the effects of 
fertilizer, reducing the amount of fertilizer lost (Fang et al., 2018). According to Liu et al. (2018), the addition of hydrochar to the soil can increase the effects of the fertilizer by reducing the number of nutrients lost by leaching and runoff. In contrast, the largest number of publications reflects the use of hydrocharging to reduce greenhouse gases (GHG), in recognition of the need to reduce emissions to mitigate climate change. The second-largest number of studies is related to the use of hydrochar associated with water retention capacity. The hydrochar can also favor water retention, increasing the total pore volume and decreasing the apparent density of the soil, which will allow more water to be maintained in the medium (Abel et al., 2013; Fang et al., 2018).

Investigations of hydrochar's potentialities regarding the immobilization of cadmium in the soil, as well as their speciation, availability, and uptake by plants have been reported too (Ren et al., 2017). Besides the mentioned potentialities, the main justification pointed in the literature for the use of hydrochar in the agricultural area is based on its greater biodegradability, which is important in materials used to improve the soil (Kruse e Dahmen, 2015). In this aspect, the phytotoxicity of the compound should be considered, owing to the presence of components soluble in the aqueous phase of hydrothermal carbonization, such as phenols, for example, which may be retained in the hydrochar structure (Kruse e Dahmen, 2015) and cause contamination.

As shown, hydrochar and its disposal in the soil are advertised in several articles as a solution to mitigate GHG emissions and carbon sequestration while providing both agricultural and environmental benefits. However, the effects of hydrochar on soil biota have not received due attention. Studies in the literature about the long-term deposition of hydrochar in the soil are still scarce. This deficiency makes it difficult to understand the mechanisms by which the material influences microbial diversity, soil community composition, fauna, plant roots etc., (Lehmann et al., 2011; C. Zhang et al., 2019) As the effects of hydrochar on soil fauna are still misunderstood, it is a barrier to the enhancement of hydrothermal carbonization in ecological systems and natural capital for social and environmental well-being.

\subsection{Energy from hydrochar, solid fuel and capacitor}

Hydrothermal carbonization can remove a portion of the ash-forming alkaline materials during combustion (Heidari et al., 2018). This characteristic allows the hydrochar to be used directly as fuel to generate energy since they have high energetic densities (Fang et al., 2018). In addition, inorganic minerals typically present in the ashes, such as $\mathrm{Si}, \mathrm{K}, \mathrm{Na}, \mathrm{S}, \mathrm{Cl}, \mathrm{P}, \mathrm{Ca}$, $\mathrm{Mg}$, and Fe may cause toxic emissions, fouling, slag and corrosion in combustors (Yang et al., 2016). In addition to using it directly as a solid fuel for power generation, the hydrochar can also be employed to synthesize fuel cell, supercapacitors of electrodes and batteries (Fang et al., 2018; Yang et al., 2016), thus acting as a means to convert and store energy.

Fig. 6 summarizes the number of publications between 2014-2019 related to hydrochar's energy and fuel potentials. It is observed that the direct application of solid fuel overlaps the 
others, representing $74.71 \%$ of publications in the last 6 years. Then there is the synthesis of batteries (11.88\%), supercapacitor electrodes (7.28\%) and fuel cells (6.13\%). The extension of publications related to the direct use of hydrochar as a solid fuel is due to the ease of use of the material without the need for modifications. Although considered an alternative source of energy, the effects of the direct and continuous use of hydrochar as a solid fuel still need further clarification. In this context, it is still a challenge to understand the environmental impacts associated with the continued use of hydrochar as a solid fuel.

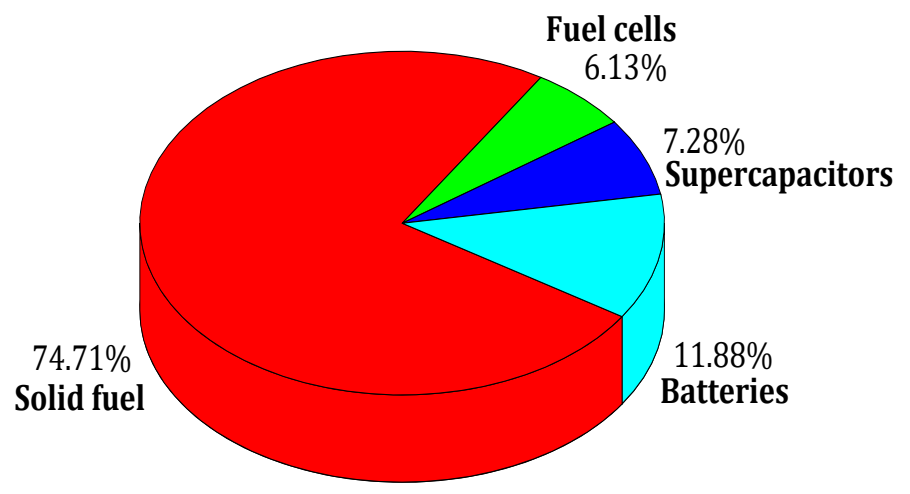

Fig. 5. Number of publications related to hydrochar's fuel and energy application.

The use of hydrochar in the synthesis of fuel cells, supercapacitor electrodes and batteries is generally associated with its low cost (Fang et al., 2018; Gao et al., 2015). However, it is not common practice in the works to evaluate the consumption associated with hydrochar production (water, energy, goods, etc.), as well as the costs associated with the synthesis and final destination of products obtained for energy storage). Therefore, the low-price justification of hydrochar for application in energy storage must be rethought. Given the need to maximize material functionality without compromising environmental resources, fuel cell development and significant market penetration have not yet been achieved. This observation is clearly observed by observing the low rate of publications on the topic (6.13\%), as shown in Fig.6. This factor is associated with the challenges facing fuel cells today as a function; cost and reliability (J. Wang et al., 2018). Thus, barriers to commercialization, life cycle analysis and the potential of fuel cells obtained via hydrothermal carbonization must be overcome for a future low carbon green economy.

\subsection{Medical applications}

In the medical area, fluorescent carbon nanoparticles $(\mathrm{FCN})$ have gained attention in recent decades because of their unique and safe fluorescent properties. Applying this concept to hydrothermal carbonization, Ruan et al. (2014) studied the development of biological markers from hydrochar obtained via hydrothermal carbonization of silk and evaluated their potential in the acquisition of medicinal images. The authors developed a biomarker with lower amounts of 
potentially toxic metals compared to those synthesized from other sources. The obtained product also presented hemocompatibility, low toxicity, and high cellular absorption. In addition, it is also possible to cite the work of Vandarkuzhali et al. (2017), involving the hydrothermal carbonization of the banana pseudo-stem as a source of carbon for sensors and bioimaging, and the work of Ensafi et al. (2017), who demonstrated promising results in the synthesis of carbon points from hydrothermal carbonization of saffron to prilocaine identification.

The most current methods of synthesis of fluorescent carbon nanoparticles face challenges such as the use of toxic precursors, complex separation procedures and low quantum yields (Ma et al., 2019). In addition, most materials obtained so far have yields of less than $10 \%$ (Gedda et al., 2016; Ma et al., 2019). In this context, hydrothermal carbonization has been pointed out as an efficient and environmentally friendly method to obtain these materials. However, the use of high temperatures and large quantities of reagents to accelerate chemical reactions results in the production of chemical residues and process control problems during reactions. In addition, it is still a challenge to obtain homogeneously sized materials to control luminescent properties. Thus, the junction between hydrothermal carbonization and fluorescent carbon nanoparticle production demonstrates a simple, green way to prepare carbon-bonded functional groups without involving highly toxic chemicals and complex purification processes.

\subsection{Hydrochars as alternative adsorbents for pollution control and remediation.}

The application of hydrochar in adsorption processes is based on the development of alternative adsorbents to the traditional activated carbons. In this regard, hydrochar is mainly used in the removal of molecules and contaminants in aqueous media, and several studies are reported in the literature regarding the adsorption capacity of these materials (Chen et al., 2015) for different types of contaminants due to their diverse oxygenated functional groups (Fang et al., 2018; Nogueira et al., 2019). Fig. 7 provides general information on research progress related to the use of hydrochar as an adsorbent to remove contaminants from the environment. $41.63 \%$ of the main studies are related to the removal of heavy metals (lead, cadmium, copper, and nickel), while $41.13 \%$ refers to organic contaminants (dyes, drugs, and pesticides). However, a small number of researches (17.24\%) also address the removal of nitrogen and phosphate.. 


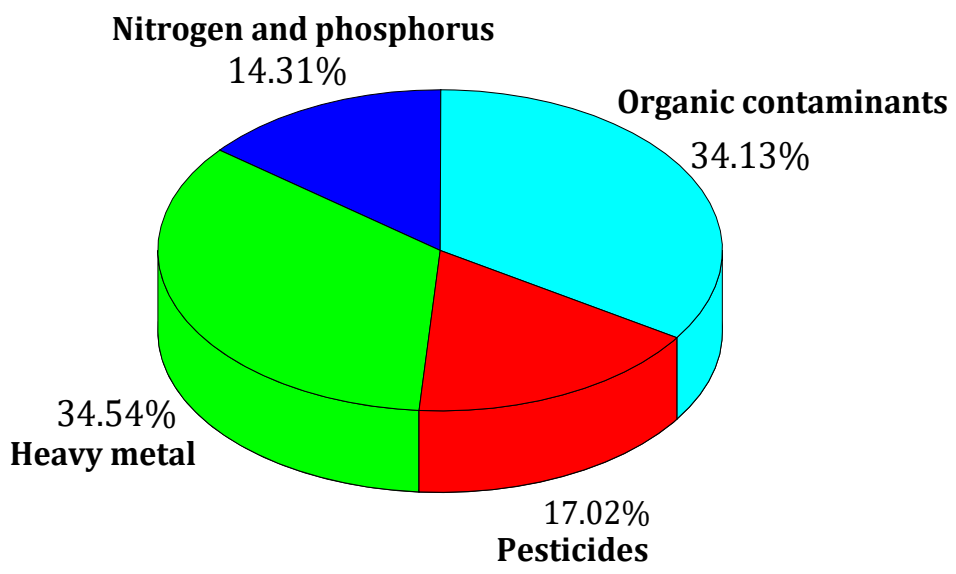

Fig. 6. Number of publications related to the use of hydrochars as an adsorbent for the removal of different contaminants types.

Fig. 8 summarizes the number of publications related to the use of hydrochar for heavy metal removal. The largest number of studies (30.44\%) refers to the removal of copper, followed by removal of lead (28.97\%), nickel (24.85\%) and cadmium (15.74\%). Jian et al. (2018) for example, produced biochar and hydrochar from the rice husk at different temperatures and used as an adsorbent for the removal of methylene blue, iodine and copper in aqueous solution. The results showed higher adsorption capacities of copper and methylene blue for the hydrochar, indicating that the main mechanisms of adsorption in these materials occur by exchange and complexation of ions, whereas in the biochar the adsorption is preferable of a superficial physical nature.

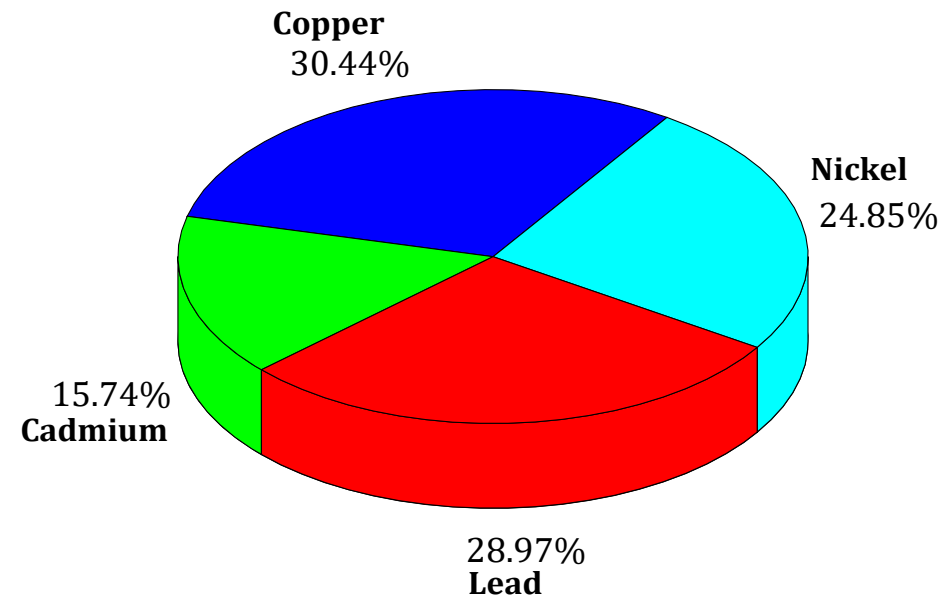

Fig. 7. Number of publications related to the use of hydrochars as an adsorbent for the removal of different heavy metal.

Several studies in the literature show that hydrochar has a high capacity to adsorb polar and nonpolar organic contaminants due to its surface functionalities (Fang et al., 2018; Gao et al., 2018; Nogueira et al., 2019). As shown in Fig. 9, 62.99\% of the studies refer to dye removal, $16.28 \%$ depict drug removal and $20.74 \%$ are related to antibiotic removal. Among contaminants, the main target of the studies is the removal of methylene blue (35.08\%) (Azharul Islam et al., 
2015; Jian et al., 2018; Nogueira et al., 2019; Ronix et al., 2017), which can be explained by the cationic characteristics of the dye. This property allows hydrochar to be used directly in the adsorption process due to the greater interaction between the methylene blue molecule and the oxygenated functional groups (OFGs) present on the hydrochar surface, particularly carboxylic acids, which have a significant influence on the adsorption properties (Zhou et al., 2017).

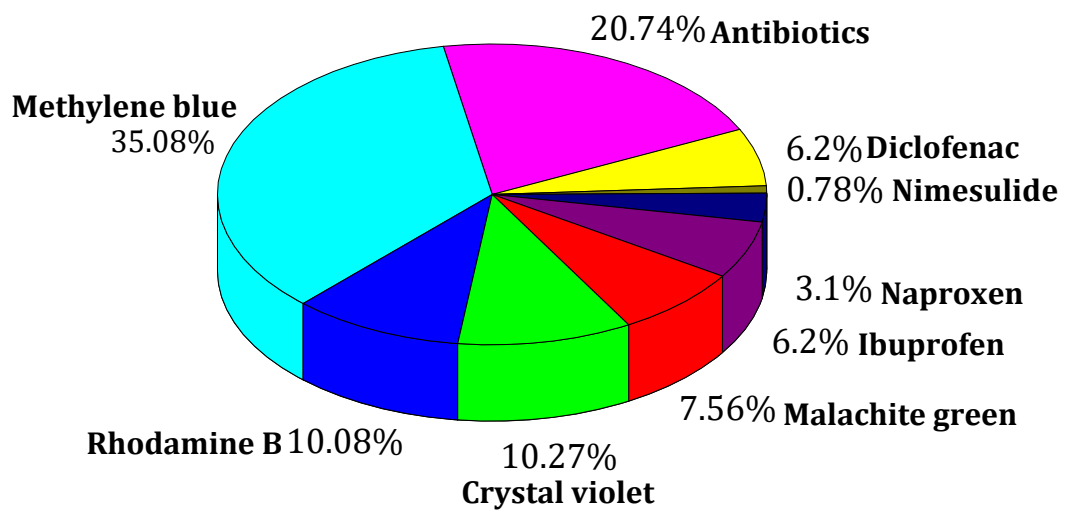

Fig. 8. Number of publications related to the use of hydrochars as an adsorbent for the removal of different oganic contaminants.

The smallest number of publications related to the application of hydrochar in the removal of antibiotics (20.74\%), and drugs such as ibuprofen (6.2\%); naproxen (3.10\%); nimesulide $(0.78 \%)$ and diclofenac $(6.2 \%)$, mainly refers to the need for hydrochar modification for insertion of specific functional groups and improvement of porous structure. (Fang et al., 2018; Li et al., 2019; S. Zhang et al., 2019b). Fang et al. (2018), for example, in a hydrothermal carbonization experiment associated with the production of a lanthanum doped material for phosphate removal, demonstrated a high affinity for phosphate in the modified hydrochar, which ranged from $30.0 \mathrm{mg} \mathrm{g}^{-1}$ of $\mathrm{P}$ adsorbed in the original material, to $61.57 \mathrm{mg} \mathrm{g}^{-1}$ in the modified hydrochar.

Although the hydrochar can be directly used in the removal of contaminants in water, further work is needed to understand the adsorption mechanisms, reuse/regeneration processes, desorption alternatives, and disposal of contaminated hydrochars. These strategies are essential in a clean production concept since the hydrochar after adsorption process is loaded with contaminant molecules. Moreover, there are few studies in the literature that detail in detail the specific adsorption mechanisms of hydrochar, such as that approached by Xia et al. (2019). Research such as these will provide a comprehensive overview of the use of hydrochar in the removal of various contaminants and a theoretical basis for optimizing hydrothermal carbonization in the development of hydrochars for targeted environmental applications. 


\subsection{Hydrochar modification to obtain activated carbon.}

Activated carbons (CA) are carbonaceous materials with high specific surface area, well developed porous structure and a wide spectrum of surface functional groups (González-García, 2018). Currently, the productivity of activated carbon is increasing due to the possibility of preparing materials with different particle sizes, high mechanical strength, high adsorption capacity, and high pore size distribution (Laginhas et al., 2016). They also stand out for their multifunctionality, presenting direct applications as catalysts, removal of pollutants (Sophia e Lima, 2018), carbon sequestration, gas storage (Wong et al., 2018), fuel cells (Giddey et al., 2012), cell biology (Selvi et al., 2008), etc. Several works are cited in the literature aiming to increase the porosity of these materials, through different activating agents, activating conditions (Fang et al., 2016; Liu et al., 2018; Sevilla e Fuertes, 2016) and alternative pretreatment. Among these, the hydrothermal carbonization stands out (Islam et al., 2015; Jain et al., 2015; Ledesma et al., 2018; Mestre et al., 2015).

The methodology is indicated as more advantageous than pyrolysis, since the initial step of drying the biomass is not necessary, which increases the variety of precursors, including biomass with high moisture content. Lower temperatures $\left(180-250{ }^{\circ} \mathrm{C}\right)$ are used in the process, and the gases produced during heating $\left(\mathrm{CO}_{2}, \mathrm{NO}_{2}, \mathrm{SO}_{2}\right.$, etc. $)$ react with water to form an acidic solution which can also act as a catalyst, thus being eliminated the need to treat such gaseous pollutants (Wong et al., 2018). The presence of several functional groups, especially oxygenated ones, on the surface of hydrochar is also reported, which catalyzes the activation processes and aids the development of texture and surface properties (Fuertes et al., 2010). Fang et al., (2016), for example, developed carbons activated from hydrochar obtained from peanut hull and physical activation with $\mathrm{CO}_{2}$. After activation, the specific surface areas of the hydrochars increased significantly, as well as the ability to adsorb contaminants (methylene blue, lead, copper, and cadmium) in aqueous solution. In another study, the chemical activation of hydrochars proved to be efficient in obtaining activated carbon with high capacity for the removal of potentially toxic metals (Fang et al., 2018). Benstoem et al. (2018) produced activated carbon employed hydrothermal carbonization and chemical activation with $\mathrm{KOH}$. The obtained materials were used efficiently in the removal of organic micropollutants in wastewater treatment plants.

The removal of emerging contaminants such as drugs, pesticides and endocrine disruptors in hydrochar modified from chemical and physical activation is also cited in the literature (Antero et al., 2019; Fang et al., 2018; Fernandez et al., 2015). The hydrochar of orange peel was activated with $\mathrm{H}_{3} \mathrm{PO}_{4}$, under $\mathrm{CO}_{2}$ and air flow, and later evaluated in the removal of salicylic acid, ibuprofen and diclofenac sodium (Fernandez et al., 2015). Chung et al. (2016), reported the removal of Escherichia coli with hydrochars produced from maize crop residues 
and activated with $\mathrm{KOH}$. Hydrochar obtained from lignocellulosic biomass Magonia pubescens fruit bark was modified from physical activation with steam and evaluated in the removal of the endocrine disruptor Bisphenol-A Antero et al. (2019). The results indicated the combination between both methodologies as an efficient way of preparing an eco-friendly adsorbent for the removal of bisphenol-A, using a lower temperature and no chemical reagents in any of the processing stages.

Although hydrochar activation is widely used in the development of activated carbon for application in adsorption and catalysis processes, Sevilla and Fuertes (2016) have explored the development of $\mathrm{AC}$ in association with hydrothermal carbonization and chemical activation for supercapacitor electrodes. Using $\mathrm{KHCO}_{3}$ as an activating agent, the authors observed a significant increase of $10 \%$ in the activated carbon yield, spherical morphology and specific surface areas of greater than $2000 \mathrm{~m}^{2} \mathrm{~g}^{-1}$, characteristics that led to satisfactory performances in supercapacitor electrodes. Supercapacitors are more promising electrochemical energy storage devices due to their high power, high energy density and long service life (J. Wang et al., 2018).

Hydrochars are of interest for the production of activated carbon because they have a high density of oxygenated functional groups, which make them efficient as precursors in activation processes. However, the union between both processes must be rethought. Specifically, on chemical activation, hydrothermal carbonization is most advantageous when the precursor has a high moisture content, on the contrary, the methodology will not be as efficient being, because it can increase the process steps. Among the several works consulted, it was observed that chemical activation was the most used. Depending on the type of biomass and considering the current environmental focus, the physical activation of the hydrochar may be more adequate. This type of activation allows to replace the traditional pyrolysis and to use lower temperatures, allowing obtaining eco-friendly materials, without the use of chemical reagents in any stage of the process and with less energy consumption.

\section{Importance and recirculation of water in hydrothermal carbonization}

In hydrothermal carbonization, usually, water is added to the system in the proportion of 3 to 10 times the mass of the dry biomass (Mumme et al., 2011). Considering a plant on an industrial scale, the continuous supply of water will be one of the challenges for its operation, which may not be an economic process. For example, producing $1 \mathrm{t}(103 \mathrm{~kg})$ hydrochar, assuming a maximum yield of 50\%, and a solid charge ratio of 1: 6 biomass (dry) to water, would require $12 \mathrm{t}$ of liquid water (Kambo and Dutta, 2015). On an industrial scale, this water demand may exceed hydrochar's applicability in terms of production cost. Detailed investigations also have shown that the aqueous phase of hydrothermal carbonization consists mainly of organic acids (formic, acetic, lactic and propionic), sugars (glucose, fructose, and xylose), furans (furfural and 5-HMF), phenols (phenol, guaiacol), cresol and catechol (Köchermann et al., 2018; Reza et al., 
2014). Disposal through wastewater treatment technologies is possible, but it can be expensive. Therefore, the organic matter must be reduced before the aqueous phase is discarded, leading to more investments and operating costs (Köchermann et al., 2018). In this regard, in order to make the process more economically feasible and environmentally friendly, an alternative is needed for treating and/or use the liquid fraction resulting from hydrothermal carbonization.

Several alternatives were proposed and discussed in the literature to make hydrothermal carbonization more economically feasible and environmentally correct. Some studies were conducted using the aqueous phase as the raw material for anaerobic digestion (Erdogan et al., 2015; Wirth et al., 2015). Another possibility that has been explored and with promising results is the reuse of water in the own hydrothermal carbonization (Catalkopru et al., 2017; Chen et al., 2015; Köchermann et al., 2018). Through recirculation, the water generated during the process is separated from the hydrochar and re-mixed in the reactor with the precursor biomass. This procedure can be performed as often as desired, according to the amount of water required for the process. In this regard, Leng and Zhou (2018), review the development, chemical compositions and wastewater properties derived from the hydrothermal carbonization of biomass. The relationships between the properties of the aqueous phase, the biomass compositions, and the processing conditions were discussed, as well as the reaction pathways which give rise to the compounds present in the resulting aqueous fraction.

The aqueous phase of the hydrothermal carbonization is composed of phenolic derivatives, organic and furanic compounds, such as acid, formic acid, glycolic acid, levulinic acid and 2,5-hydroxyl methyl furfural (HMF), which are formed during the degradation of the lignocellulosic biomass (Kambo and Dutta, 2015). Products like levulinic acid are key building blocks for obtaining chemicals and materials. The 2,5-HMF is a versatile chemical with the potential to replace various petroleum-based products. Both levulinic acid and 2,5-HMF have been identified as "the 12 major value-added chemicals in biomass" by the US Department of Energy (DOE) (US Department of Energy, 2014). Thus, the identification, recovery, and characterization of these intermediate compounds could act as a potential platform in a biorefinery system from hydrothermal carbonization (Kambo and Dutta, 2015).

Stemann et al. (2013) argue that recirculation of the aqueous phase from hydrothermal carbonization may increase the acidity of the hydrochar, and consequently improve its fuel properties. The authors also report that recirculation can reduce the amount of wastewater and treatment costs before disposal. In addition, simulations have shown that recirculation can be an efficient means of recovering heat and, therefore, reducing external heat consumption by up to tenfold. The concentration of organic acids in the water can also increase the higher heating value and the carbon concentration in the hydrochar. Thus, energy density intensification will occur as a consequence of additional polymerization of dissolved organic substances. Reza et al. (2016) report the treatment of residual water from the hydrothermal carbonization of manure from dairy 
and effluent. The authors observed that after oxidative treatment, water presented lower amounts of total organic carbon and short-chain organic acids, which are not considered to be toxic to the environment (Reza et al., 2016). Thus, oxidative treatment may be an alternative for the treatment of the aqueous phase resulting from hydrothermal carbonization.

Kambo et al. (2018) analyzed the recirculation of the aqueous phase during the hydrothermal carbonization of Miscanthus and observed a high content of organic acids, HMF (hydroxy-methyl-furfural) and total organic carbon. The authors also demonstrated that the acidity of the process water increased with increasing temperature and with the recirculation process. Related to mass yield, the authors reported an increase between 5-10\% in mass yield and $15 \%$ in hydrochars energy. More expressively, the higher heating value (HHV) of the hydrochars increased from 18.9 (precursor biomass) to $26.6 \mathrm{MJ} \mathrm{kg}^{-1}$ (maximum value) during recirculation. The increase in mass yield is due to the increase of water acidity in the hydrothermal process, which leads to different chemical routes and product formation (Ghanim et al., 2016; Heidari et al., 2018) through the processes of repolymerization.

The influence of residual water recirculation on hydrochar properties is described in a contradictory way. Stemann et al. (2013), for example, reported that carbon content and HHV (higher heating value) increased, while Catalkopru et al. (2017) observed decreases in carbon content and HHV after the first recirculation stage. Köchermann et al. (2018) studied the influence of aqueous phase recirculation and temperature during hydrothermal carbonization. The main emphasis of the authors was to verify the temperature variation and its impact on the accumulation or depletion of organic components in the hydrochar and liquid fractions. The results showed that the yield of the hydrochar increased with the progression of the recirculation, which was intensified with the increase in temperature. However, the higher heating value (HHV) was not affected by the recirculation process. The analysis of the aqueous phase showed an accumulation of total organic carbon (TOC), chemical oxygen demand (COD) and organic acids (acetic, formic, lactic and propionic).

Process water recirculation can be considered as a viable method for the treatment and recycling of the aqueous phase, both by reducing the amount of water for the process and increasing of economic character. However, it should not be the only alternative and methodologies such as biological degradation, for example, should be considered. Much of the available literature on water recirculation of the hydrothermal process has gaps in the application of hydrochar and the water phase itself after recirculation cycles. The main objective of the works in this context is to recirculate the water and later to characterize the fractions generated after certain previously established cycles. Thus, in addition to characterization, the application of products generated after recirculation studies should be considered in order to understand the real effects on the environment, the treatment and recovery pathways. 


\section{Perspectives and alternatives for a cleaner production}

Several articles in the literature point to hydrothermal carbonization as an environmentally friendly methodology and appropriate to the principles of green chemistry. However, some factors need to be considered and the technique still needs to overcome some challenges. Most of the authors consider the use of low temperatures and the use of water to create reactional media as justifications for the sustainability of the process, which has led to thousands of publications using various types of biomass. In the articles consulted for the elaboration of the review, no author mentioned or presented alternatives for the final destination of the liquid and gaseous wastes originated during the process. There is, therefore, a large gap in the literature regarding the use of residual fractions obtained from hydrothermal carbonization, as well as its final destination. In this respect, the use of hydrochar has been the main focus of research, and there is no concern among researchers about the possible formation of toxic compounds that can be eliminated in the environment. Analyzes of toxic, cytotoxic and genotoxic effects on products in waste products derived from hydrothermal carbonization, for example, are not discussed.

In the agricultural area, the addition of hydrochar to the soil should be carefully analyzed. Hydrochar may contain in its composition metals and other potentially toxic compounds. The presence of these components may pose a threat to the environment through soil pollution and latent toxicity, affecting the biota of microorganisms and disrupting food chains. Therefore, the use of hydrothermal carbonization as a cleaner, more environmentally friendly and sustainable production should be based on an extensive evaluation of the ecotoxicological properties of hydrochar and its effect on soil biota in a long timeline, in order to avoid a possible environmental imbalance.

Cost, durability, and reliability are the main challenges in the commercialization of fuel cells, capacitors and batteries obtained through hydrothermal carbonization and modification methodologies. In a clean production system, the junction between hydrothermal carbonization and energy storage should consider the feasibility of manufacturing processes, use of appropriate materials, quality, product cost, the resilience of supply chains, life cycle, and supply chain. value. Priority shifting is needed that focuses not only on product potential but on system integration to significantly increase reliability, durability, cost savings and the introduction of recycling methodologies.

Fluorescent carbon nanoparticles represent an attractive approach to the development of green chemistry. Considering a clean production system, obtaining these materials via hydrothermal carbonization needs to overcome obstacles related to increased yield, nanomaterial size homogeneity, low carbon toxicity sources, and no acid/alkaline reagents. In addition, concerns about segregation, treatment and proper disposal of waste should be the responsibilities and priorities of research groups. The immediate objective in the area should be to reduce energy 
consumption, product cleanliness, and waste disposal. In the long term, efficiency should be improved and eventually low-toxicity chemical synthesis performed. These alternatives are also relevant in the junction between hydrothermal carbonization and obtaining activated carbons. Modification strategies of the hydrochar can be used for the development of materials with a porous structure developed and able to act in adsorption processes and industrial processes of catalysis. Although activation/modification methodologies are consolidated in the literature, new syntheses and alternative and clean methods should be considered in a context of sustainable development, using lower temperatures, lower energy costs and reduced use of chemical reagents.

Some aspects related to the use of hydrochar as alternative adsorbents also need to be discussed. Specifically, on the adsorption processes, it is necessary to consider hydrochar treatment methodologies for the elimination of adsorbed contaminants, which is rarely presented in the literature. In order to make the technique more sustainable, studies involving cycles of reuse of the adsorbent should be extended, for example determining the efficiency of the adsorbent as a function of time. It is important to mention the importance of physicochemical characterization, such as chemical oxygen demand, color, turbidity, etc., in the water after adsorption processes using hydrochar. These analyses are important for the detection of potential substances present in the hydrochar structure and that can migrate to the aqueous medium during the adsorption process, contaminating it with new molecules that have high chemical stability, photochemistry and a very slow rate of biodegradation.

There is no consensus in the literature regarding the use of catalysts in hydrothermal carbonization. In a clean production system, the use of heterogeneous catalysts can aid in the development of materials with higher yield and process efficiency. However, there are gaps in the literature regarding the use of catalysts as well as their maintenance, stability, and regeneration. Exploring the use of catalysts and addressing the shortcomings addressed is essential to improve their performance and minimize deactivation during hydrothermal reactions. In this context, the association between hydrothermal carbonization with the activation process may be a promising approach for the development of alternative catalysts based on activated carbons and used in the hydrothermal process itself.

Although results from the literature show that process water recirculation can significantly reduce water consumption and increase energy recovery efficiency, little is known about the agricultural, medical, adsorbent and fuel potential of hydrochars following various recirculation cycles. Accumulation of heavy metals in hydrochars, for example, may affect agricultural applications. In contrast, the increase in oxygenated functional groups may be beneficial in adsorption processes. To become an efficient technique in clean production processes, understanding process size and water reuse should not only be done in recirculation studies but in all processes based on the HTC methodology, regardless of the application of the generated products. Thus, some of the key future directions related to hydrothermal carbonization 
are in the integration of the recirculation process with other aspects of process system engineering, such as supply chain scheduling, planning, control, and management.

Considering a cleaner production system, hydrothermal carbonization can perfectly fit in a biorefinery platform, allowing the simultaneous production of several products. However, discussions about this simultaneous production are scarcely mentioned in the literature. In this context, the technique has been utilized decentralized, only as a hydrothermal pretreatment for separation of the lignocellulosic biomass in its structural components and subsequent conversion into products of interest. It is worth clarifying here the versatility of the methodology since many researchers still cannot distinguish it and often the term hydrothermal carbonization is not well understood. Regardless of the nomenclature, in general, processes with liquid water under high temperature and pressure are also known as autohydrolysis, hydrothermal treatment, hydrothermal process, compressed hot water process (CHW), etc. Similar to hydrothermal carbonization, the reaction mechanisms that occur in these processes are the same, differing only in the reaction conditions. Thus, in any of the cited processes, all types of biomass conversion in the hydrothermal environment are sustained by the rapid hydrolysis of the precursor in water and self-generated pressures.

Based on the above considerations, in a biorefinery process, the sustainable approach of the hydrothermal carbonization can be rewritten, considering the concept of clean production and the lignocellulosic biomass, as shown in Fig. 10. During HTC, the lignocellulosic components will be exposed to water in the subcritical state, which will penetrate the cellular structures and cause depolymerization of the less resistant fragments. These fragments will migrate to the hydrochar and to the aqueous phase. The hydrochar can be used to obtain solid fuel, as a precursor for activated carbon, in the agricultural area (it can return to the precursor lignocellulosic biomass), in adsorption processes (allowing treated wastewater to be reused in the hydrothermal process), etc. In addition, due to the deconstruction of the lignocellulosic matrix, the cellulose exposed and present in the hydrochar can be submitted to biotechnological processes (acid or enzymatic hydrolysis) to obtain biofuel. Simultaneously, due to its highly resistant nature, much of the lignin present in the lignocellulosic matrix remains in the hydrochar structure, which makes it possible to use it as a precursor to obtaining macromolecules and aromatic. 


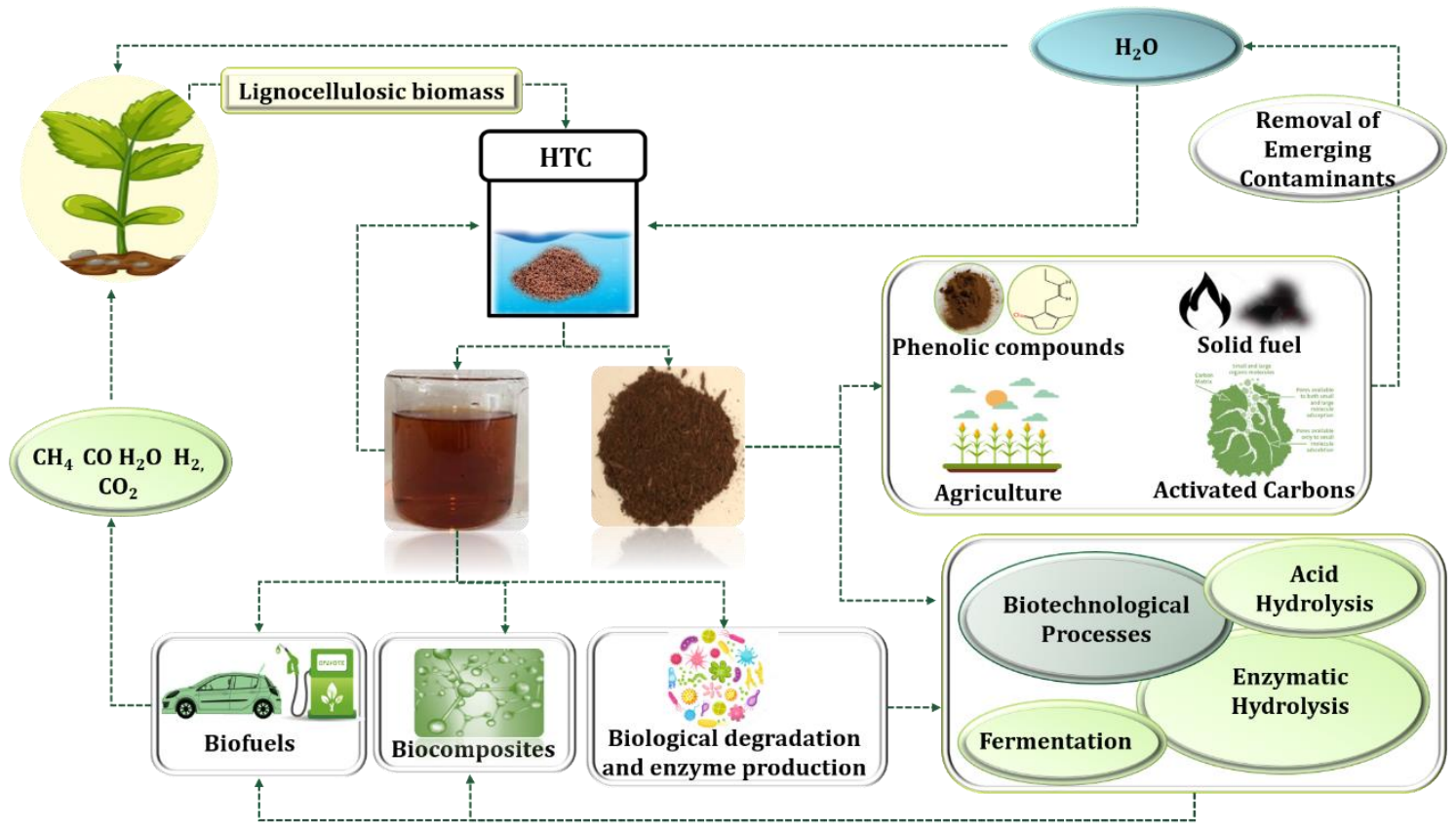

Fig. 9. A sustainable approach to the hydrothermal carbonization of lignocellulosic biomass for the simultaneous production of different products in a biorefinery platform considering the concept of cleaner production.

The aqueous fraction resulting from the hydrothermal carbonization may contain various biocomposites of interest, due to the depolymerization of less resistant lignocellulosic compounds. At moderate hydrothermal temperatures, hemicellulose can be decomposed into valuable products, such as oligosaccharides, monosaccharides, furfural compounds, acetic acid, xylooligosaccharides, etc. Depending on the reaction conditions, the aqueous phase of the hydrothermal carbonization may further contain phenolic compounds of interest, resulting from the solubilization of lignin fragments and the breakdown of lignin-cellulose-hemicellulose bonds. Considered as byproducts of the hydrothermal processing of lignocellulosic biomass, these compounds are attractive sources for natural antioxidants and food additives. However, the extraction and purification of these compounds are still challenging, making the use of the aqueous phase of hydrothermal carbonization an obstacle to clean production. In this context, the activated carbon obtained from the hydrochar can be an alternative purification, which increases the potential of the technique. The aqueous fraction may also contain various toxic substances, making it necessary to treat it prior to disposal, which may occur by biological degradation using microorganisms, for example.

The use of yeasts may be a strategy for the treatment of residual water from hydrothermal carbonization. Simultaneously, it is also possible to obtain viable enzymatic cocktails in the saccharification processes, whereby the complex sugars of the lignocellulosic biomass (polysaccharides) are depolymerized and decomposed into simple sugars. To compose a microbial platform for the production of the set of enzymes compatible with the essential phases of second-generation ethanol production (fermentation and saccharification) would be a 
promising strategy for the optimization of hydrothermal carbonization. In this aspect, the simultaneous accomplishment of the mentioned processes can reduce the costs of the hydrothermal methodology, since the reactions take place in a single reactor and there is reagent saving. Thus, in future applications, it is expected that the hydrothermal carbonization of the lignocellulosic biomass can be used as an eco-friendly technology for the simultaneous production of different types of products on an industrial scale. In this way, a combination of hydrothermal methodology with other processes will help to develop viable quality products in a cleaner production concept.

\section{Final considerations}

Applied as a pretreatment or to obtain hydrochar, and related to a biorefinery concept, hydrothermal carbonization is positioned as a promising methodology for the conversion of lignocellulosic biomass to value-added products, which was widely discussed during the review. However, it is necessary to understand the mechanisms involved in the technique and the result of the degradation of the biomass in the hydrothermal atmosphere, which is still under discussion, and there is no consensus in the literature. This is due in large part to the challenges for the development of reactors that allow immediate analyzes with the modifications of the parameters, the main variables responsible for the hydrochar physicochemical properties. Despite a large number of studies on the of hydrochar in recent years, the liquid and gaseous fraction resulting from hydrothermal carbonization has few discussions and uses. These fractions may contain byproducts and molecules of interest and also undesirable, necessitating detailed analyzes for an intense understanding of hydrothermal carbonization, in relation to hydrochar formation and byproducts on a theoretical and experimental basis. In addition, post-treatment and recirculation strategies for residual water after hydrothermal treatment should be considered, aiming at both the recovery and utilization of important nutrients and the reduction of water consumption. These strategies are necessary to make the methodology even broader, sustainable and perfectly suited to cleaner production processes.

\section{Acknowledgements}

To the University of Brasília (UNB), the Laboratory of Materials and Fuels (LMC) and the Federal Institute of Goiás (IFG), for technical support. To the Coordenação de Aperfeiçoamento de Pessoal de Nível Superior (CAPES) for Ph.D. scholarships.

\section{Declaration of interest conflit}

Declarations of interest: the authors declare that they have no conflict of interest. 


\section{References}

Abel, S., Peters, A., Trinks, S., Schonsky, H., Facklam, M., Wessolek, G., 2013. Impact of biochar and hydrochar addition on water retention and water repellency of sandy soil. Geoderma 202-203, 183-191. doi:10.1016/j.geoderma.2013.03.003

Achinas, S., Achinas, V., Euverink, G.J.W., 2017. A Technological Overview of Biogas Production from Biowaste. Engineering 3, 299-307. doi:https://doi.org/10.1016/J.ENG.2017.03.002

Adams, P., Bridgwater, T., Lea-Langton, A., Ross, A., Watson, I., 2018. Chapter 8 - Biomass Conversion Technologies BT - Greenhouse Gas Balances of Bioenergy Systems. Academic Press, p. 107-139. doi:https://doi.org/10.1016/B978-0-08-101036-5.00008-2

Antero, R.V.P., Alves, A.C.F., de Tarso Ferreira Sales, P., Oliveira, S.B. de, Ojala, S.A., Brum, S.S., 2019. A new approach to obtain mesoporous-activated carbon via hydrothermal carbonization of Brazilian Cerrado biomass combined with physical activation for bisphenol-A removal. Chem. Eng. Commun. 0, 1-17. doi:10.1080/00986445.2019.1601625

Anumol, T., Vijayanandan, A., Park, M., Philip, L., Snyder, S.A., 2016. Occurrence and fate of emerging trace organic chemicals in wastewater plants in Chennai, India. Environ. Int. 9293, 33-42. doi:https://doi.org/10.1016/j.envint.2016.03.022

Bargmann, I., Rillig, M.C., Buss, W., Kruse, A., Kuecke, M., 2013. Hydrochar and biochar effects on germination of spring barley. J. Agron. Crop Sci. 199, 360-373. doi:10.1111/jac. 12024

Benstoem, F., Becker, G., Firk, J., Kaless, M., Wuest, D., Pinnekamp, J., Kruse, A., 2018. Elimination of micropollutants by activated carbon produced from fibers taken from wastewater screenings using hydrothermal carbonization. J. Environ. Manage. 211, 278286. doi:https://doi.org/10.1016/j.jenvman.2018.01.065

Bentsen, N.S., Felby, C., Thorsen, B.J., 2014. Agricultural residue production and potentials for energy and materials services. Prog. Energy Combust. Sci. 40, 59-73. doi:10.1016/J.PECS.2013.09.003

Besse, X., Schuurman, Y., Guilhaume, N., 2015. Hydrothermal conversion of lignin model compound eugenol. Catal. Today 258, 270-275. doi:https://doi.org/10.1016/j.cattod.2014.12.010

Bocken, N.M.P., Short, S.W., Rana, P., Evans, S., 2014. A literature and practice review to develop sustainable business model archetypes. J. Clean. Prod. 65, 42-56. doi:https://doi.org/10.1016/j.jclepro.2013.11.039

Cai, J., He, Y., Yu, X., Banks, S.W., Yang, Y., Zhang, X., Yu, Y., Liu, R., Bridgwater, A. V., 2017. Review of physicochemical properties and analytical characterization of lignocellulosic biomass. Renew. Sustain. Energy Rev. 76, 309-322. doi:10.1016/J.RSER.2017.03.072

Cai, J., Li, B., Chen, C., Wang, J., Zhao, M., Zhang, K., 2016. Hydrothermal carbonization of tobacco stalk for fuel application. Bioresour. Technol. 220, 305-311. doi:https://doi.org/10.1016/j.biortech.2016.08.098

Catalkopru, A.K., Kantarli, I.C., Yanik, J., 2017. Effects of spent liquor recirculation in hydrothermal carbonization. Bioresour. Technol. 226, 89-93. doi:https://doi.org/10.1016/j.biortech.2016.12.015 
Chen, X., Li, Z., Wei, L., Li, X., Liu, S., Gu, J., 2015. Fabrication of hierarchical cabbage-like carbonaceous materials by one-step cobalt-assisted hydrothermal carbonization of furfural. Microporous Mesoporous Mater. 210, 149-160.

doi:10.1016/J.MICROMESO.2015.02.036

Chen, X., Lin, Q., Zhao, X., Li, G., He, R., 2017. Hydrochar production from watermelon peel by hydrothermal carbonization. Bioresour. Technol. 241, 236-243. doi:10.1016/J.BIORTECH.2017.04.012

Chen, X., Ma, X., Peng, X., Lin, Y., Wang, J., Zheng, C., 2018. Effects of aqueous phase recirculation in hydrothermal carbonization of sweet potato waste. Bioresour. Technol. 267, 167-174. doi:https://doi.org/10.1016/j.biortech.2018.07.032

Chung, J.W., Breulmann, M., Clemens, A., Fühner, C., Foppen, J.W., Lens, P.N.L., 2016. Simultaneous removal of rotavirus and adenovirus from artificial ground water using hydrochar derived from swine feces. J. Water Health 14, 754-767. doi:10.2166/wh.2016.010

Eibisch, N., Helfrich, M., Don, A., Mikutta, R., Kruse, A., Ellerbrock, R., Flessa, H., 2013. Properties and Degradability of Hydrothermal Carbonization Products. J. Environ. Qual. 42, 1565-1573. doi:10.2134/jeq2013.02.0045

Ensafi, A.A., Hghighat Sefat, S., Kazemifard, N., Rezaei, B., Moradi, F., 2017. A novel onestep and green synthesis of highly fluorescent carbon dots from saffron for cell imaging and sensing of prilocaine. Sensors Actuators B Chem. 253, 451-460. doi:10.1016/J.SNB.2017.06.163

Erdogan, E., Atila, B., Mumme, J., Reza, M.T., Toptas, A., Elibol, M., Yanik, J., 2015. Characterization of products from hydrothermal carbonization of orange pomace including anaerobic digestibility of process liquor. Bioresour. Technol. 196, 35-42. doi:https://doi.org/10.1016/j.biortech.2015.06.115

Fang, J., Gao, B., Zimmerman, A.R., Ro, K.S., Chen, J., 2016. Physically (CO2) activated hydrochars from hickory and peanut hull: preparation, characterization, and sorption of methylene blue, lead, copper, and cadmium. RSC Adv. 6, 24906-24911. doi:10.1039/C6RA01644H

Fang, J., Zhan, L., Ok, Y.S., Gao, B., 2018. Minireview of potential applications of hydrochar derived from hydrothermal carbonization of biomass. J. Ind. Eng. Chem. 57, 15-21. doi:https://doi.org/10.1016/j.jiec.2017.08.026

Fang, Z., Sato, T., Smith, R.L., Inomata, H., Arai, K., Kozinski, J.A., 2008. Reaction chemistry and phase behavior of lignin in high-temperature and supercritical water. Bioresour. Technol. 99, 3424-3430. doi:https://doi.org/10.1016/j.biortech.2007.08.008

Fernandez, M.E., Ledesma, B., Román, S., Bonelli, P.R., Cukierman, A.L., 2015. Development and characterization of activated hydrochars from orange peels as potential adsorbents for emerging organic contaminants. Bioresour. Technol. 183, 221-228. doi:10.1016/j.biortech.2015.02.035

Fuertes, A.B., Arbestain, M.C., Sevilla, M., MacIá-Agulló, J.A., Fiol, S., López, R., Smernik, R.J., Aitkenhead, W.P., Arce, F., MacIas, F., Macías, F., 2010. Chemical and structural properties of carbonaceous products obtained by pyrolysis and hydrothermal carbonisation of corn stover. Soil Res. 48, 618-626. doi:10.1071/SR10010

Funke, A., Ziegler, F., 2010a. Hydrothermal carbonization of biomass: A summary and discussion of chemical mecha nisms for process engineering. Biofuels, Bioprod. 
Biorefining 4, 160-177. doi:10.1002/bbb.198

Funke, A., Ziegler, F., 2010b. Hydrothermal carbonization of biomass: A summary and discussion of chemical mechanisms for process engineering. Biofuels, Bioprod. Biorefining 4, 160-177. doi:10.1002/bbb.198

Gallifuoco, A., Taglieri, L., Scimia, F., Papa, A.A., Di Giacomo, G., 2017. Hydrothermal carbonization of Biomass: New experimental procedures for improving the industrial Processes. Bioresour. Technol. 244, 160-165. doi:https://doi.org/10.1016/j.biortech.2017.07.114

Gao, F., Shao, G., Qu, J., Lv, S., Li, Y., Wu, M., 2015. Tailoring of porous and nitrogen-rich carbons derived from hydrochar for high-performance supercapacitor electrodes. Electrochim. Acta 155, 201-208. doi:https://doi.org/10.1016/j.electacta.2014.12.069

Gao, P., Zhou, Y., Meng, F., Zhang, Y., Liu, Z., Zhang, W., Xue, G., 2016. Preparation and characterization of hydrochar from waste eucalyptus bark by hydrothermal carbonization. Energy 97, 238-245. doi:10.1016/j.energy.2015.12.123

Gao, Y., Liu, Y., Zhu, G., Xu, J., xu, H., Yuan, Q., Zhu, Y., Sarma, J., Wang, Y., Wang, J., Ji, L., 2018. Microwave-assisted hydrothermal carbonization of dairy manure: Chemical and structural properties of the products. Energy 165, 662-672. doi:https://doi.org/10.1016/j.energy.2018.09.185

Gedda, G., Lee, C.-Y., Lin, Y.-C., Wu, H., 2016. Green synthesis of carbon dots from prawn shells for highly selective and sensitive detection of copper ions. Sensors Actuators B Chem. 224, 396-403. doi:https://doi.org/10.1016/j.snb.2015.09.065

Ghanim, B.M., Pandey, D.S., Kwapinski, W., Leahy, J.J., 2016. Hydrothermal carbonisation of poultry litter: Effects of treatment temperature and residence time on yields and chemical properties of hydrochars. Bioresour. Technol. 216, 373-380. doi:10.1016/j.biortech.2016.05.087

Giddey, S., Badwal, S.P.S., Kulkarni, A., Munnings, C., 2012. A comprehensive review of direct carbon fuel cell technology. Prog. Energy Combust. Sci. 38, 360-399. doi:https://doi.org/10.1016/j.pecs.2012.01.003

González-García, P., 2018. Activated carbon from lignocellulosics precursors: A review of the synthesis methods, characterization techniques and applications. Renew. Sustain. Energy Rev. 82, 1393-1414. doi:https://doi.org/10.1016/j.rser.2017.04.117

Goyal, H.B., Seal, D., Saxena, R.C., 2008. Bio-fuels from thermochemical conversion of renewable resources: A review. Renew. Sustain. Energy Rev. 12, 504-517. doi:https://doi.org/10.1016/j.rser.2006.07.014

Heidari, M., Dutta, A., Acharya, B., Mahmud, S., 2018. A review of the current knowledge and challenges of hydrothermal carbonization for biomass conversion. J. Energy Inst. doi:https://doi.org/10.1016/j.joei.2018.12.003

Islam, M. Azharul, Benhouria, A., Asif, M., Hameed, B.H., 2015. Methylene blue adsorption on factory-rejected tea activated carbon prepared by conjunction of hydrothermal carbonization and sodium hydroxide activation processes. J. Taiwan Inst. Chem. Eng. 52, 57-64. doi:10.1016/j.jtice.2015.02.010

Islam, Md. Azharul, Tan, I.A., Benhouria, A., Asif, M., Hamei, B.H., 2015. Mesoporous and adsorptive properties of palm date seed activated carbon prepared via sequential hydrothermal carbonization and sodium hydroxide activation. Chem. Eng. J. 270, 187195. doi:10.1016/j.cej.2015.01.058 
Jain, A., Balasubramanian, R., Srinivasan, M.P., 2016. Hydrothermal conversion of biomass waste to activated carbon with high porosity: A review. Chem. Eng. J. 283, 789-805. doi:10.1016/j.cej.2015.08.014

Jain, A., Balasubramanian, R., Srinivasan, M.P., 2015. Tuning hydrochar properties for enhanced mesopore development in activated carbon by hydrothermal carbonization. Microporous Mesoporous Mater. 203, 178-185. doi:10.1016/j.micromeso.2014.10.036

Jian, X., Zhuang, X., Li, B., Xu, X., Wei, Z., Song, Y., Jiang, E., 2018. Comparison of characterization and adsorption of biochars produced from hydrothermal carbonization and pyrolysis. Environ. Technol. Innov. 10, 27-35. doi:10.1016/j.eti.2018.01.004

Kambo, H.S., Dutta, A., 2015. A comparative review of biochar and hydrochar in terms of production, physico-chemical properties and applications. Renew. Sustain. Energy Rev. 45, 359-378. doi:10.1016/j.rser.2015.01.050

Kambo, H.S., Minaret, J., Dutta, A., 2018. Process Water from the Hydrothermal Carbonization of Biomass: A Waste or a Valuable Product? Waste and Biomass Valorization 9, 11811189. doi:10.1007/s12649-017-9914-0

Kang, S., Li, X., Fan, J., Chang, J., 2012. Characterization of Hydrochars Produced by Hydrothermal Carbonization of Lignin, Cellulose, d-Xylose, and Wood Meal. Ind. Eng. Chem. Res. 51, 9023-9031. doi:10.1021/ie300565d

Köchermann, J., Görsch, K., Wirth, B., Mühlenberg, J., Klemm, M., 2018. Hydrothermal carbonization: Temperature influence on hydrochar and aqueous phase composition during process water recirculation. J. Environ. Chem. Eng. 6, 5481-5487. doi:https://doi.org/10.1016/j.jece.2018.07.053

Kruse, A., Dahmen, N., 2018. Hydrothermal biomass conversion: Quo vadis? J. Supercrit. Fluids 134, 114-123. doi:https://doi.org/10.1016/j.supflu.2017.12.035

Kruse, A., Dahmen, N., 2015. Water - A magic solvent for biomass conversion. J. Supercrit. Fluids 96, 36-45. doi:https://doi.org/10.1016/j.supflu.2014.09.038

Kumar, M., Olajire Oyedun, A., Kumar, A., 2018. A review on the current status of various hydrothermal technologies on biomass feedstock. Renew. Sustain. Energy Rev. 81, 17421770. doi:https://doi.org/10.1016/j.rser.2017.05.270

Laginhas, C., Nabais, J.M.V., Titirici, M.M., 2016. Activated carbons with high nitrogen content by a combination of hydrothermal carbonization with activation. Microporous Mesoporous Mater. 226, 125-132. doi:10.1016/j.micromeso.2015.12.047

Ledesma, B., Olivares-Marín, M., Álvarez-Murillo, A., Roman, S., Nabais, J.M.V., 2018. Method for promoting in-situ hydrochar porosity in hydrothermal carbonization of almond shells with air activation. J. Supercrit. Fluids 138, 187-192. doi:https://doi.org/10.1016/j.supflu.2018.04.018

Lehmann, J., Rillig, M.C., Thies, J., Masiello, C.A., Hockaday, W.C., Crowley, D., 2011. Biochar effects on soil biota - A review. Soil Biol. Biochem. 43, 1812-1836. doi:https://doi.org/10.1016/j.soilbio.2011.04.022

Leng, L., Zhou, W., 2018. Chemical compositions and wastewater properties of aqueous phase (wastewater) produced from the hydrothermal treatment of wet biomass: A review. Energy Sources, Part A Recover. Util. Environ. Eff. 40, 2648-2659. doi:10.1080/15567036.2018.1495780

Li, Y., Tsend, N., Li, T., Liu, H., Yang, R., Gai, X., Wang, H., Shan, S., 2019. Microwave 
assisted hydrothermal preparation of rice straw hydrochars for adsorption of organics and heavy metals. Bioresour. Technol. 273, 136-143. doi:https://doi.org/10.1016/j.biortech.2018.10.056

Liu, F., Dai, Y., Zhang, S., Li, J., Zhao, C., Wang, Y., Liu, C., Sun, J., 2018. Modification and application of mesoporous carbon adsorbent for removal of endocrine disruptor bisphenol A in aqueous solutions. J. Mater. Sci. 53, 2337-2350. doi:10.1007/s10853-017-1705-2

Ma, X., Li, S., Hessel, V., Lin, L., Meskers, S., Gallucci, F., 2019. Synthesis of luminescent carbon quantum dots by microplasma process. Chem. Eng. Process. - Process Intensif. 140, 29-35. doi:https://doi.org/10.1016/j.cep.2019.04.017

Mestre, A.S., Tyszko, E., Andrade, M.A., Galhetas, M., Freire, C., Carvalho, A.P., 2015. Sustainable activated carbons prepared from a sucrose-derived hydrochar: remarkable adsorbents for pharmaceutical compounds. RSC Adv. 5, 19696-19707. doi:10.1039/C4RA14495C

Missaoui, A., Bostyn, S., Belandria, V., Cagnon, B., Sarh, B., Gökalp, I., 2017. Hydrothermal carbonization of dried olive pomace: Energy potential and process performances. J. Anal. Appl. Pyrolysis 128, 281-290. doi:10.1016/J.JAAP.2017.09.022

Mumme, J., Eckervogt, L., Pielert, J., Diakité, M., Rupp, F., Kern, J., 2011. Hydrothermal carbonization of anaerobically digested maize silage. Bioresour. Technol. 102, 9255-9260. doi:10.1016/j.biortech.2011.06.099

Nakason, K., Panyapinyopol, B., Kanokkantapong, V., Viriya-empikul, N., Kraithong, W., Pavasant, P., 2018. Characteristics of hydrochar and hydrothermal liquid products from hydrothermal carbonization of Cassava rhizome. J. Energy Inst. J. 91, 184-193. doi:10.1016/j.joei.2017.01.002

Nakason, K., Panyapinyopol, B., Kanokkantapong, V., Viriya-empikul, N., Kraithong, W., Pavasant, P., 2018. Hydrothermal carbonization of unwanted biomass materials: Effect of process temperature and retention time on hydrochar and liquid fraction. J. Energy Inst. 91, 786-796. doi:10.1016/j.joei.2017.05.002

Nanda, S., A. Kozinski, J., K. Dalai, A., 2016. Lignocellulosic biomass: A review of conversion technologies and fuel products. Curr. Biochem. Eng. 3, 24-36. doi:10.2174/2213385203666150219232000

Nizamuddin, S., Baloch, H.A., Griffin, G.J., Mubarak, N.M., Bhutto, A.W., Abro, R., Mazari, S.A., Ali, B.S., 2017. An overview of effect of process parameters on hydrothermal carbonization of biomass. Renew. Sustain. Energy Rev. 73, 1289-1299. doi:https://doi.org/10.1016/j.rser.2016.12.122

Nogueira, G.D.R., Duarte, C.R., Barrozo, M.A.S., 2019. Hydrothermal carbonization of acerola (Malphigia emarginata D.C.) wastes and its application as an adsorbent. Waste Manag. 95, 466-475. doi:https://doi.org/10.1016/j.wasman.2019.06.039

Ren, J., Wang, F., Zhai, Y., Zhu, Y., Peng, C., Wang, T., Li, C., Zeng, G., 2017. Effect of sewage sludge hydrochar on soil properties and $\mathrm{Cd}$ immobilization in a contaminated soil. Chemosphere 189, 627-633. doi:https://doi.org/10.1016/j.chemosphere.2017.09.102

Reza, M.T., Freitas, A., Yang, X., Coronella, C.J., 2016. Wet Air Oxidation of Hydrothermal Carbonization (HTC) Process Liquid. ACS Sustain. Chem. Eng. 4, 3250-3254. doi:10.1021/acssuschemeng.6b00292

Reza, M.T., Wirth, B., Lüder, U., Werner, M., 2014. Behavior of selected hydrolyzed and dehydrated products during hydrothermal carbonization of biomass. Bioresour. Technol. 
169, 352-361. doi:https://doi.org/10.1016/j.biortech.2014.07.010

Rizhikovs, J., Zandersons, J., Spince, B., Dobele, G., Jakab, E., 2012. Preparation of granular activated carbon from hydrothermally treated and pelletized deciduous wood. J. Anal. Appl. Pyrolysis 93, 68-76. doi:10.1016/J.JAAP.2011.09.009

Ronix, A., Pezoti, O., Souza, L.S., Souza, I.P.A.F., Bedin, K.C., Souza, P.S.C., Silva, T.L., Melo, S.A.R., Cazetta, A.L., Almeida, V.C., 2017. Hydrothermal carbonization of coffee husk: Optimization of experimental parameters and adsorption of methylene blue dye. J. Environ. Chem. Eng. 5, 4841-4849. doi:10.1016/J.JECE.2017.08.035

Ruan, S., Wan, J., Fu, Y., Han, K., Li, X., Chen, J., Zhang, Q., Shen, S., He, Q., Gao, H., 2014. PEGylated Fluorescent Carbon Nanoparticles for Noninvasive Heart Imaging. Bioconjug. Chem. 25, 1061-1068. doi:10.1021/bc5001627

Selvi, B.R., Jagadeesan, D., Suma, B.S., Nagashankar, G., Arif, M., Balasubramanyam, K., Eswaramoorthy, M., Kundu, T.K., 2008. Intrinsically Fluorescent Carbon Nanospheres as a Nuclear Targeting Vector: Delivery of Membrane-Impermeable Molecule to Modulate Gene Expression In Vivo. Nano Lett. 8, 3182-3188. doi:10.1021/nl801503m

Sevilla, M., Fuertes, A.B., 2016. A Green Approach to High-Performance Supercapacitor Electrodes: The Chemical Activation of Hydrochar with Potassium Bicarbonate. ChemSusChem 9, 1880-1888. doi:10.1002/cssc.201600426

Sophia, A.C., Lima, E.C., 2018. Removal of emerging contaminants from the environment by adsorption. Ecotoxicol. Environ. Saf. 150, 1-17. doi:https://doi.org/10.1016/j.ecoenv.2017.12.026

Stemann, J., Putschew, A., Ziegler, F., 2013. Hydrothermal carbonization: Process water characterization and effects of water recirculation. Bioresour. Technol. 143, 139-146. doi:https://doi.org/10.1016/j.biortech.2013.05.098

Tekin, K., Karagöz, S., Bektaş, S., 2014. A review of hydrothermal biomass processing. Renew. Sustain. Energy Rev. 40, 673-687. doi:https://doi.org/10.1016/j.rser.2014.07.216

Titirici, M.M., Antonietti, M., 2010. Chemistry and materials options of sustainable carbon materials made by hydrothermal carbonization. Chem. Soc. Rev. 39, 103-16. doi:10.1039/b819318p

Tu, R., Sun, Y., Wu, Y., Fan, X., Wang, J., Shen, X., He, Z., Jiang, E., Xu, X., 2019. Effect of surfactant on hydrothermal carbonization of coconut shell. Bioresour. Technol. 284, 214221. doi:https://doi.org/10.1016/j.biortech.2019.03.120

US Department of Energy, 2014. Top Value Added Chemicals From Biomass.

Vandarkuzhali, S.A.A., Jeyalakshmi, V., Sivaraman, G., Singaravadivel, S., Krishnamurthy, K.R., Viswanathan, B., 2017. Highly fluorescent carbon dots from Pseudo-stem of banana plant: Applications as nanosensor and bio-imaging agents. Sensors Actuators B Chem. 252, 894-900. doi:10.1016/J.SNB.2017.06.088

Vorwerk, S., Somerville, S., Somerville, C., 2004. The role of plant cell wall polysaccharide composition in disease resistance. Trends Plant Sci. 9, 203-209. doi:10.1016/J.TPLANTS.2004.02.005

Wang, J., Wang, H., Fan, Y., 2018. Techno-Economic Challenges of Fuel Cell Commercialization. Engineering 4, 352-360. doi:https://doi.org/10.1016/j.eng.2018.05.007 
Wang, S., Dai, G., Yang, H., Luo, Z., 2017. Lignocellulosic biomass pyrolysis mechanism: A state-of-the-art review. Prog. Energy Combust. Sci. 62, 33-86. doi:https://doi.org/10.1016/j.pecs.2017.05.004

Wang, T., Zhai, Y., Zhu, Y., Li, C., Zeng, G., 2018. A review of the hydrothermal carbonization of biomass waste for hydrochar formation: Process conditions, fundamentals, and physicochemical properties. Renew. Sustain. Energy Rev. 90, 223-247. doi:https://doi.org/10.1016/j.rser.2018.03.071

Wirth, B., Reza, T., Mumme, J., 2015. Influence of digestion temperature and organic loading rate on the continuous anaerobic treatment of process liquor from hydrothermal carbonization of sewage sludge. Bioresour. Technol. 198, 215-222. doi:https://doi.org/10.1016/j.biortech.2015.09.022

Wohlgemuth, S., 2012. Functional Nanostructured Hydrothermal Carbons for Sustainable Technologies : Heteroatom Doping and Superheated Vapor.

Wong, S., Ngadi, N., Inuwa, I.M., Hassan, O., 2018. Recent advances in applications of activated carbon from biowaste for wastewater treatment: A short review. J. Clean. Prod. 175, 361-375. doi:10.1016/J.JCLEPRO.2017.12.059

Wu, Q., Yu, S., Hao, N., Wells, T., Meng, X., Li, M., Pu, Y., Liu, S., Ragauskas, A.J., 2017. Characterization of products from hydrothermal carbonization of pine. Bioresour. Technol. 244, 78-83. doi:https://doi.org/10.1016/j.biortech.2017.07.138

Xia, Y., Yang, T., Zhu, N., Li, D., Chen, Z., Lang, Q., Liu, Z., Jiao, W., 2019. Enhanced adsorption of $\mathrm{Pb}$ (II) onto modified hydrochar: Modeling and mechanism analysis. Bioresour. Technol. 288, 121593. doi:https://doi.org/10.1016/j.biortech.2019.121593

Yan, W., Acharjee, T.C., Coronella, C.J., Vásquez, V.R., 2009. Thermal pretreatment of lignocellulosic biomass. Environ. Prog. Sustain. Energy 28, 435-440. doi:10.1002/ep. 10385

Yan, W., Hastings, J.T., Acharjee, T.C., Coronella, C.J., Vásquez, V.R., 2010. Mass and Energy Balances of Wet Torrefaction of Lignocellulosic Biomass. Energy \& Fuels 24, 4738-4742. doi:10.1021/ef901273n

Yang, W., Wang, H., Zhang, M., Zhu, J., Zhou, J., Wu, S., 2016. Fuel properties and combustion kinetics of hydrochar prepared by hydrothermal carbonization of bamboo. Bioresour. Technol. 205, 199-204. doi:10.1016/j.biortech.2016.01.068

Zhang, B., Huang, H.-J., Ramaswamy, S., 2008. Reaction Kinetics of the Hydrothermal Treatment of Lignin. Appl. Biochem. Biotechnol. 147, 119-131. doi:10.1007/s12010-0078070-6

Zhang, C., Zeng, G., Huang, D., Lai, C., Chen, M., Cheng, M., Tang, W., Tang, L., Dong, H., Huang, B., Tan, X., Wang, R., 2019. Biochar for environmental management: Mitigating greenhouse gas emissions, contaminant treatment, and potential negative impacts. Chem. Eng. J. 373, 902-922. doi:https://doi.org/10.1016/j.cej.2019.05.139

Zhang, S., Zhu, X., Zhou, S., Shang, H., Luo, J., Tsang, D.C.W., 2019a. and Its Application, in: Biochar from Biomass and Waste - Fundamentals and Applications. p. 275-294. doi:10.1016/B978-0-12-811729-3.00015-7

Zhang, S., Zhu, X., Zhou, S., Shang, H., Luo, J., Tsang, D.C.W., 2019b. Chapter 15 Hydrothermal Carbonization for Hydrochar Production and Its Application, in: Ok, Y.S., Tsang, D.C.W., Bolan, N., Novak, J.M. (Orgs.), Biochar from Biomass and Waste. Elsevier, p. 275-294. doi:https://doi.org/10.1016/B978-0-12-811729-3.00015-7 
Zhou, N., Chen, H., Xi, J., Yao, D., Zhou, Z., Tian, Y., Lu, X., 2017. Biochars with excellent $\mathrm{Pb}$ (II) adsorption property produced from fresh and dehydrated banana peels via hydrothermal carbonization. Bioresour. Technol. 232, 204-210. doi:https://doi.org/10.1016/j.biortech.2017.01.074 